\title{
RESEARCH ON THE CONSTRUCTION METHOD OF COMPREHENSIVE EVALUATION INDEX OF GEOGRAPHIC CONDITIONS
}

\author{
S. H. Lva, b, *, J. X. Zhang c ${ }^{\text {, Z. H. Zhang }}{ }^{\text {a }}$ J. C. Jiao ${ }^{\text {a }}$ \\ ${ }^{a}$ Qingdao Geotechnical Investigation and Surveying Institute, State and Local Joint Engineering Research Center for the Integration \\ and Applicatioin of Sea-land Geographical Information, Shandong Road, Qingdao, China - (1shmm2001@aliyun.com, \\ 18763902787@163.com, zmdjjchjjch@163.com) \\ ${ }^{\mathrm{b}}$ College of Environmental Science and Engineering, Ocean University of China, Songling Road, Qingdao, China - \\ 1shmm2001@aliyun.com \\ ${ }^{c}$ National Quality Inspection and Testing Center for Surveying and Mapping Products, Renmin Road West, Beijing, China - \\ zhangjx@ casm.ac.cn
}

Commission VII, WG VII/6

KEY WORDS: Geographic conditions, Index, Mathematical method, Evaluation

\begin{abstract}
:
This article proposes a construction method for a comprehensive geographic conditions evaluation index based on geographic conditions survey data combined with thematic data on society, economy, ecology and population. This article constructs a threelevel evaluation framework composed of index level, object level and factor level from the perspectives of ecological coordination, urban development, regional economic potential and basic public services, studies a method of acquiring all-level factor data on geographic conditions and discusses the comprehensive evaluation factor system of geographic conditions. The components of the all-level index are selected through principal component analysis, and iterative analysis is performed by innovatively setting conditions to ensure the independence of the factors and establish an evaluation factor set for geographic conditions. The weighting for the all-level index is obtained through the analytic hierarchy process resulting in the index of geographic conditions. From the perspective of geographic conditions, this article makes a dynamic and quantitative evaluation of national conditions and strengths to provide a reference basis for regional sustainable development and governmental management decisions. By using the method, this article first obtains the index of geographic conditions of Q city with comprehensive evaluation and analysis to verify the objectivity and scientific nature of the method and expand and deepen the application of survey data on geographic conditions.
\end{abstract}

\section{INTRODUCTION}

National conditions refer to the basic information and characteristics of a nation's social nature, politics, economy and culture, generalizing its cultural and historical traditions, natural geographic environment, social and economic development. Geographic conditions are an important part of national conditions, covering a wealth of natural and human geography information like territory, topography, land cover, transportation network, rivers and lakes, town layout, spatial distribution of population and productivity, resource environment and disaster distribution (Lian et al., 2011; Zhang et al., 2011) The statistics, analysis and research of geographic conditions is conducive to the dynamic and quantitative evaluation of national conditions and strength as it provides a reference for further optimizing the spatial pattern of land, regional economy and urban development. In addition, the analysis and prediction off untrue development directions is also a development direction and strategic requirement of "Building digital China, monitoring geographic conditions, developing industries and constructing mapping power" (Zhang et al., 2015; Zhao., 2011; Xu., 2011). Therefore, based on the survey results of geographic conditions, combined with the thematic data on population, society and economy as well as quantitative and qualitative analysis, and from the perspectives of ecological coordination, regional economic potential, basic public service and urban development, this article constructs a three-level evaluation framework composed of index level, object level and factor level, studies a method of acquiring alllevel factor data on geographic conditions, discusses the comprehensive evaluation factor system of geographic conditions, and conducts selection and weight determination of all-level factors by using mathematical methods like iteration to achieve the transformation "geographic data $\rightarrow$ information on geographic conditions $\rightarrow$ government decision".

Geographic conditions are the basis for a nation to formulate its development strategies and policies and also the objective basis for implementing these strategies and policies. Scientific evaluation principles and a perfected evaluation system are the prerequisite for accurately and comprehensively reflecting geographic conditions and future development trends ( $\mathrm{Li}$ et al., 2002; Li., 2011).

\subsection{Main principles}

Scientific construction principles shall be determined prior to the establishment of the comprehensive evaluation system of geographic conditions (Liu et al., 2014) to ensure that the factors used at all levels can truly and objectively reflect surface features and geographic phenomena, and accurately describe the changes in nature and culture and the relationship between them. The following three principles are adopted in the research.

\footnotetext{
* Corresponding author
} 
(1)The principle of focusing on survey data of geographic conditions and combining social and economic data.

This principle refers to the construction of a method for comprehensive evaluation of geographic conditions to reflect the spatial distribution of resources, environmental, ecological and economic factors and their development and change laws through the qualitative and quantitative analysis of survey data of geographic conditions combined with social and economic data.

\section{(2) The hierarchical principle}

The selection of evaluation factors (NGCSLO, 2013; Chen., 2015) needs to be adjusted or changed according to different levels of national conditions. This article constructs a threelevel evaluation framework composed of index level, object level and factor level, providing macro guidance and reflecting the pertinence of different granularities.

\section{(3)The principle of availability and operability}

Factors shall be simple and practical. In addition, factor quantization and the level of difficulty and reliability of data acquisition shall also be taken into account. This article makes a comprehensive analysis of the available data and relevant national or industry standards, selects the existing factor data as far as possible according to scientific laws, and uses the information extracted through the existing technical means of RS and GIS (Chen., 2014; Xie et al., 2015) to ensure that the evaluation factors are provided with high operability and effectiveness.

\subsection{Three-level evaluation system}

The evaluation of geographic conditions relates to a number of resource types and specific factors. This article selects the threelevel tree structure (Wu., 2012) as the basic evaluation framework, which can reflect the level of resource combinations and individual resources with great practicability and accuracy.

The first level is the comprehensive evaluation index of geographic conditions, representing the ultimate goal of evaluation of geographic conditions in a certain region and the quantitative expression of the comprehensive level of geographic conditions. It can be used to compare the comprehensive level of geographic conditions of different regions requiring the support of a second-level object. The second level is the object layer, representing a collection of all geographic resource types. It can be used to reflect the level of various resources requiring the support of a third-level factor. The third level is the factor layer. It is the most basic unit of the whole system where factor data can be acquired and operated. No single factor can replace the status of regional geographic conditions. The data at the object layer are acquired through the computation and analysis of original data using statistical methods and the data at the index layer are acquired through level superposition based on the calculated weight.

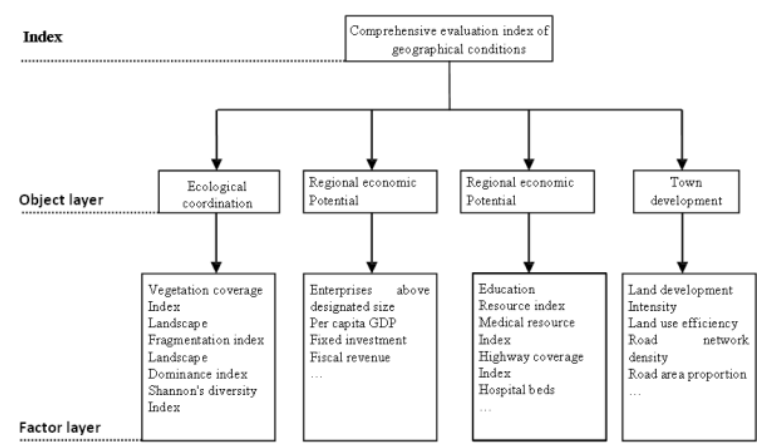

Figure 1. Three level evaluation system

\section{METHOD}

First, this article selects the impact factors related to the ecological coordination, regional economic potential, equalization of basic public services and urban development (CASM, 2013) and acquires their original data; second, preliminarily screens the Geographic conditions evaluation factor set through principal component analysis to form a candidate evaluation factor set of four object layers; third, determines the weight of candidate factors of each object layer through the analytic hierarchy process and performs correlation analysis and iteration combined with the factor data to obtain the evaluation factor set and weight of the four object layers; fourth, obtains the weight of the object layer to the index layer through the analytic hierarchy process; finally, computes the weight of two layers by superposition according to the established three-level frame work of evaluation system to obtain the final weight of a third-level factor on the first-level index and obtain the comprehensive evaluation index of regional geographic conditions combined with the original factor data.

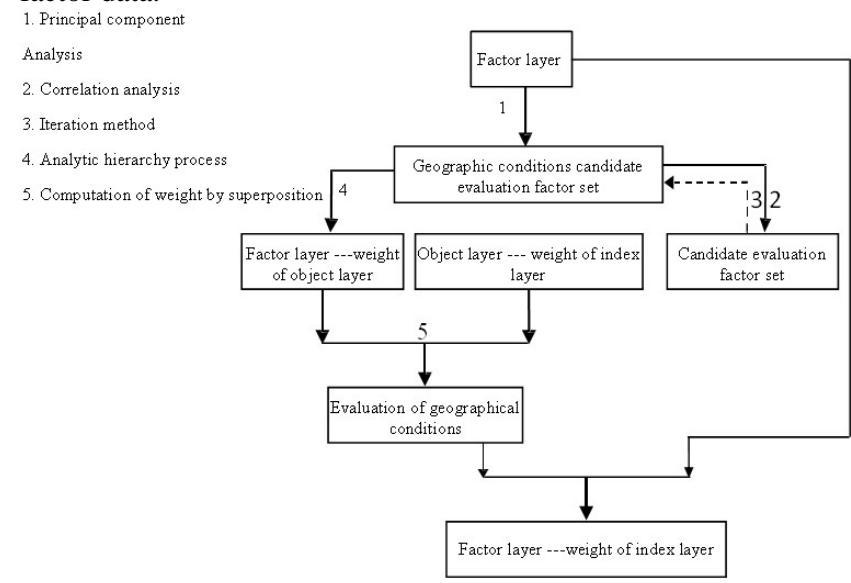

Figure 2. Evaluation process

\subsection{Acquisition of third-level factor data}

In the research, third-level comprehensive Geographic conditions evaluation factors refer to geographic elements which can be directly extracted from carriers like maps and remote sensing images or obtained by means of ground measurement. They are most basic in the system, including the name, scope, location, length and area of national conditions; most of which come from the survey database of geographic conditions including vector elements, raster maps, place names and digital elevation models, etc. According to the experts' experience, references and related guidance (CASM, 2013), this 
article first selected 44 third-level factors and grouped them into four second-level objects. The following are the factor data screened by mathematical methods (see Section 2.2) and the method of their acquisition.

\begin{tabular}{|c|c|c|}
\hline Object & Factor & \begin{tabular}{|l|} 
Acquisition method \\
\end{tabular} \\
\hline \multirow{7}{*}{$\begin{array}{l}\text { Ecological } \\
\text { coordination }\end{array}$} & Vegetation coverage index & $\begin{array}{l}\text { Acquired from the calculation of } \\
\text { arable land, garden land, } \\
\text { woodland, grassland coverage } \\
\text { and total area of administrative } \\
\text { region. }\end{array}$ \\
\hline & Landscape fragmentation & $\begin{array}{l}\text { Acquired from the calculation of } \\
\text { topography, terrain and land } \\
\text { coverage combined with the } \\
\text { factors of soil and precipitation. }\end{array}$ \\
\hline & Landscape dominance & $\begin{array}{l}\text { Acquired from the calculation of } \\
\text { the number of various patches in } \\
\text { a landscape pattern. }\end{array}$ \\
\hline & Shannon's diversity & $\begin{array}{l}\text { Acquired from the calculation of } \\
\text { the average area of patches and } \\
\text { the area of arranged patches of a } \\
\text { landscape in a landscape pattern. }\end{array}$ \\
\hline & Shannon's uniformity & $\begin{array}{l}\text { Acquired from the calculation of } \\
\text { several major landscapes in a } \\
\text { landscape pattern. }\end{array}$ \\
\hline & Water coverage & $\begin{array}{l}\text { Acquired from the calculation of } \\
\text { the area of rivers and lakes and } \\
\text { total area of administrative } \\
\text { region. }\end{array}$ \\
\hline & Drainage density & $\begin{array}{l}\text { Acquired from the calculation of } \\
\text { the area of rivers and total area of } \\
\text { an administrative region. }\end{array}$ \\
\hline \multirow{6}{*}{$\begin{array}{l}\text { Urban } \\
\text { development }\end{array}$} & Land development intensity & $\begin{array}{l}\text { Acquired from the calculation of } \\
\text { the construction area of } \\
\text { transportation and residential land } \\
\text { and total area of an administrative } \\
\text { region. }\end{array}$ \\
\hline & Land use efficiency & $\begin{array}{l}\text { Acquired from the calculation of } \\
\text { GNP and the area of an } \\
\text { administrative region. }\end{array}$ \\
\hline & Per capita green area ratio & $\begin{array}{l}\text { Acquired from the calculation of } \\
\text { population and total area of } \\
\text { arable land, garden land, } \\
\text { woodland and grassland. } \\
\end{array}$ \\
\hline & Parks & $\begin{array}{l}\text { The number of parks in an } \\
\text { administrative region. }\end{array}$ \\
\hline & Road network density & $\begin{array}{l}\text { Acquired from the calculation of } \\
\text { the total length of roads and the } \\
\text { area of an administrative region. }\end{array}$ \\
\hline & Road area proportion & $\begin{array}{l}\text { Acquired from the calculation of } \\
\text { the total road area and the area of } \\
\text { an administrative region. }\end{array}$ \\
\hline \multirow{3}{*}{$\begin{array}{l}\text { Public } \\
\text { services }\end{array}$} & Education resource coverage & $\begin{array}{l}\text { Whether any settle mentis } \\
\text { provided with schools within } \\
\text { 3KM around it. }\end{array}$ \\
\hline & Medical resource coverage & $\begin{array}{l}\text { Whether any settlement is } \\
\text { provided with hospitals within } \\
\text { 5KM around it. }\end{array}$ \\
\hline & Highway coverage & $\begin{array}{l}\text { Whether any settlement is } \\
\text { provided with freeway entry/exit } \\
\text { within 30KM around it. }\end{array}$ \\
\hline \multirow{5}{*}{$\begin{array}{l}\text { Regional } \\
\text { economic } \\
\text { potential }\end{array}$} & Enterprises above designated size & $\begin{array}{l}\text { With annual operating income of } \\
\text { more than } 20 \text { million Yuan, } \\
\text { acquired from the statistical } \\
\text { yearbook. }\end{array}$ \\
\hline & Fixed investment & $\begin{array}{l}\text { Economic activities for } \\
\text { construction and purchase of } \\
\text { fixed assets, acquired from the } \\
\text { statistical yearbook. }\end{array}$ \\
\hline & Per capita GDP & $\begin{array}{l}\text { Calculated by using GDP and } \\
\text { population and acquired from the } \\
\text { statistical yearbook. }\end{array}$ \\
\hline & Population density & $\begin{array}{l}\text { Acquired from the statistical } \\
\text { yearbook }\end{array}$ \\
\hline & Fiscal revenue & $\begin{array}{l}\text { Acquired from the statistical } \\
\text { yearbook }\end{array}$ \\
\hline
\end{tabular}

Table 1. Factor data acquisition

\subsection{Selection of comprehensive evaluation index}

\subsubsection{Standardization of original data}

After acquiring the original third-level factor Geographic conditions data, it is not possible to directly carry out numerical computation and comprehensive analysis due to different units of measurement and order of magnitude. The original data must be standardized by using mathematical methods. This article uses the ideal value analysis method (Li., 2006) to eliminate the effect of the dimensions of the original data.

The maximum factor value (the minimum value is used for negative correlation) is selected as the ideal value of the factor and the factor value of each evaluation unit is compared with its ideal value to obtain the difference between them and determine the development level of the factor in the evaluation unit.

E.g. Assume that $X_{r}$ is the ideal value of a factor and $X_{i}(\mathrm{i}=1,2 \ldots$ $\mathrm{n})$ is the actual value of the factor in each unit, then the standardized data is $\overline{X_{i}}=X_{i} / X_{r}$. The relative data replaces the original data after the calculations are performed through the ideal value method to eliminate the effect of the dimensions and enable the comparison of different indexes.

\subsubsection{Preliminary screening of factors}

The 44 preliminarily screened third-level factors, due to the difference in their importance and value, are translated from multiple variables into a few aggregate variables (i.e. the principal components) through dimensionality reduction based on principal component analysis (Zhu et al., 2011).The principal components can reflect the vast majority of information of the original variables. This method can overcome the shortcoming that single geographic factors cannot truly reflect the status of geographic conditions. A wide range of factors of national conditions are introduced while the complicated factors are summed up into several principal components to simplify complex issues and obtain more scientific and accurate in formation of geographic conditions.

After the standardization of the original factor data, it is assumed that the correlation coefficient matrix $\mathrm{R}$ is made up of $n$ evaluation indexes,

$$
\mathrm{R}=\left[\begin{array}{cccc}
r_{11} & r_{12} & \ldots & r_{1 n} \\
r_{21} & r_{22} & \ldots & r_{2 n} \\
\ldots & \ldots & \ldots & \ldots \\
r_{n 1} & r_{n 2} & \ldots & r_{n n}
\end{array}\right]
$$

In the matrix

$$
r_{i j}=\sum_{k-1}^{n}\left(X_{k i}-\bar{X}_{i}\right)\left(X_{k j}-\bar{X}_{j}\right) / \sqrt{\sum_{k-1}^{n}\left(X_{k i}-\bar{X}_{i}\right)^{2} \sum_{k-1}^{n}\left(X_{k j}-\bar{X}_{j}\right)^{2}} .
$$

The eigenvector corresponding to the maximum eigenvalue in the matrix $\mathrm{R}$ is calculated, and this eigenvector is the weight of each factor. The contribution of this factor is obtained by multiplying the weight and data value. The contribution of each factor is standardized, and the factors with a contribution of less than $2 \%$ are removed. Thus, the preliminary screening of factors of geographic conditions is completed, for Ming candidate evaluation factor set. 


\subsubsection{Correlation analysis and iterative process}

Correlation analysis (Shnitnikov., 2001) refers to the analysis of two or more correlative variable elements to measure the degree of correlation between two variable factors and achieve a better classification effect with the fewest characteristics. This article considers that the data value of a factor is positively correlated with the index second level and first level index value, that is, this factor has a positive contribution to the index value, and vice versa for negative correlation. After determining the positive or negative correlation of all factors with the index values, the correlation analysis can be performed.

If scientific analysis and effective screening are not performed on the candidate evaluation factor set of geographic conditions after it is established through principal component analysis, deviation would inevitably be produced due to human factors. The independence between factors is particularly difficult to guarantee, resulting in possible repeated or incomplete factors. Therefore, this article carries out necessary processing of the candidate factor set through the correlation analysis to promptly correct the factor system in the process of determining evaluation factors. The table below shows the results of each factor related to ecological coordination of object layer after the correlation analysis.

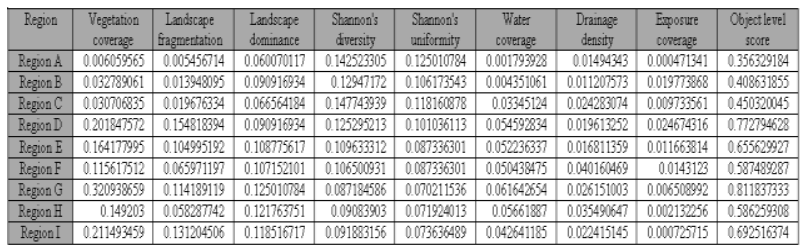

Table 2. Iterative computation I

$\mathrm{X}_{1}$ (vegetation coverage) and $\mathrm{Y}_{1}$ (exposure coverage) are the two factors of ecological coordination. $\mu_{\mathrm{x}}$ and $\mu_{\mathrm{y}}$ are their weights. According to the data and experts' experience (Sun., 2012), this article assumes that there is still some correlation between $\mathrm{X}_{1}$ and $\mathrm{Y}_{1}$. Thus, $\mu_{\mathrm{x}}$ and $\mu_{\mathrm{y}}$ are added or subtracted according to the negative correlation or positive correlation and the choice of $\mathrm{X}_{1}$ and $\mathrm{Y}_{1}$ is determined. If the newly computed index value of object level is close to the original index value (the threshold value is 0.02 ), the assumption can be regarded reasonable and the correlation satisfies the certain conditions of iteration ( $\mathrm{Lu}$ et al., 2002) as shown in the figure below. The iteration loop is carried out according to the positive or negative correlation between the data until the score of each evaluation unit is not less than the set threshold value twice, thus the Geographic conditions evaluation factor set is established.

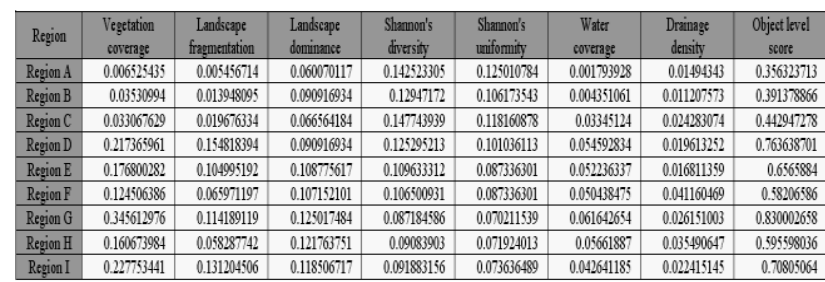

Table 3. Iterative computation II

\subsubsection{Determination of evaluation factor weight}

Weight refers to the importance of a factor in the overall evaluation (Cai., 2005) and can be used to distinguish a group of evaluation factors. After the determination of the evaluation factor set, the corresponding weight system shall be established. $W_{\mathrm{ij}}(\mathrm{i}, \mathrm{j}=1,2 \ldots \mathrm{p})$ is the correlation coefficient of the original variables $X_{\mathrm{i}}$ and $X_{\mathrm{j}}$ (obtained from the pair wise comparison by relevant experts), and $W$ is the real symmetric matrix (i.e. $W_{\mathrm{ij}}=$ $W_{\mathrm{ji}}$ ).The eigenvector $\mathrm{A}$ corresponding to the maximum eigenvalue of the matrix is calculated. If the eigenvector satisfies the consistency check of the matrix, then A is the factor weight. It contains the element size reflecting the impact of each factor. According to this principle, the weight of third-level factor on second-level object and the weight of second-level object on first-level index are calculated, and then the final weight of third-level factor on first-level index is obtained by multiplying the weights of two levels through superposition.

\section{CONCLUSION}

With the Geographic conditions index, decision-making support can be provided to the municipal administrators carrying out assessment and evaluation, formulating development strategies and plans, adjusting economic structure layout, transforming economic development mode and promoting urbanization development withal great significance for ecological management, resource management, major project construction and five-in-one development. On this basis, normal monitoring of geographic conditions can be carried out, strengthening the implementation of performance evaluations by local government in terms of ecological civilization construction, quality improvement and building a resource-saving and environmentally-friendly society. The factors of geographic conditions involving nine administrative units of $\mathrm{Q}$ city are first extracted based on the evaluation system, and the comprehensive indexes of regional geographic conditions are acquired through the appropriate mathematical calculations. The results are shown in the table below.

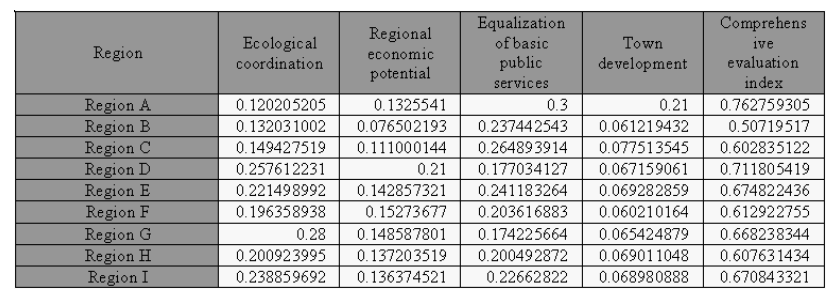

Table 4. Comprehensive evaluation index of geographic conditions

Region A, with the highest comprehensive index, scores highest on the index of equalization of basic public services and urban development, reflecting its natural advantages as the main urban zone, e.g. reasonable and adequate allocation of health, education and retirement facilities, high land development intensity and land use efficiency, high economic output.

Region D, with the second-highest comprehensive index, scores highest on the index of ecological coordination and regional economic potential, reflecting its basic conditions of large fixed investment, rich natural resources and strengthening as a new national area.

Region E, with the third-highest comprehensive index, has implemented the urban development layout of scattering the old town, building the new town and connecting the eastern town in recent years, becoming one of the hot economic are as of the city with good basic conditions and great potential for economic and social development and ecological civilization construction; 
Region I, with the fourth-highest comprehensive index, is a typical strong economic area with better industrial base, high vegetation coverage, preferable ecological base and excellent urban infrastructure.

Region B, with the lowest comprehensive index is close to the main urban zone with excellent infrastructure, but its development is severely obstructed by the National Nature Reserve in the east. Great efforts need to be exerted on urban village renovation, service improvement, and intensive land use and output increase in the future. The table below shows the situation of comprehensive index of geographic conditions of the administrative units in Q city through hypsometric tinting.

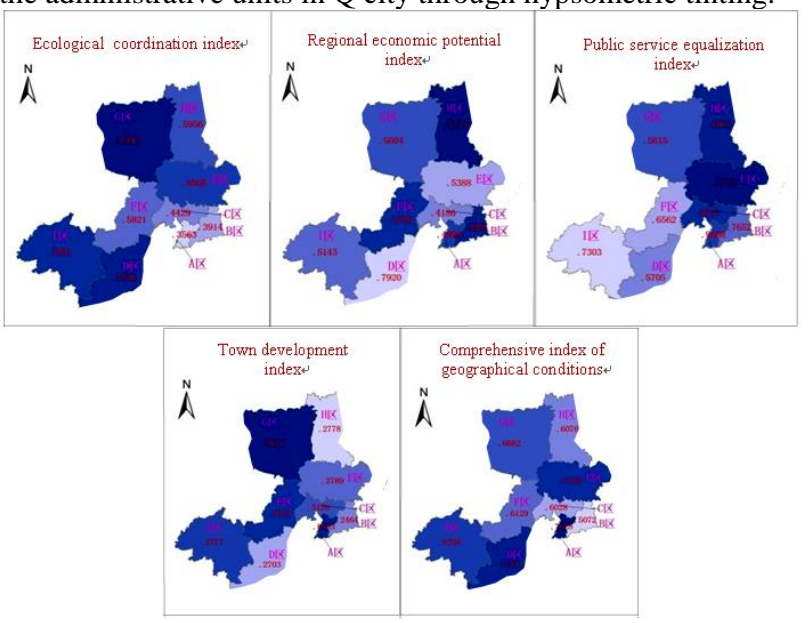

Figure 3. Index and object layer data

\section{PROSPECT}

Geographic conditions are an important basis for formulating regional development strategies and plans, adjusting economic structure and productivity space layout and transforming the economic development mode to achieve management decisions and scientific development. Currently, research on the comprehensive evaluation of geographic conditions is relatively sparse. Due to the differences in basic information of various regions, geographic conditions cannot be comprehensively evaluated for the lack of a complete set of standards. This article has carried out a computation of the index of national conditions of the administrative units in $\mathrm{Q}$ city and performed a general analysis of the results based on the survey data of geographic conditions and combined with the thematic data of society and economy from the perspectives of ecological coordination, town development, regional economic potential and basic public services. The three-level tree structure composed of index layer, object layer and factor layer was utilized and the viewpoint of reflecting factor combination and individual factors to review and use the Geographic conditions data was taken, with the expectations of discovering new characteristics and rules to support development decisionmaking.

In the process of constructing the comprehensive evaluation index of geographic conditions, this article combined the specific contents and technical characteristics of each index and referred to the existing methods related to monitoring and statistical analysis, but further research needs to be conducted in the following aspects:

1. Completeness of selected factors and correctness of factor combination. Since each geographic element has its own properties and characteristics, specific research and a large number of experiments shall be conducted on each type of geographic element; the scientific selection of third-level factor when combining with the object layer also greatly affects the final results;

2. Method of acquisition of third-level factors. The third-level factors selected in the research are available and operable. Some factors which may have an impact on the comprehensive evaluation of national conditions but whose data cannot be acquired or operated on are not included;

3. Weight setting. Although the experience of many experts is considered in the weight setting through the analytic hierarchy process, the method is actually subjective on an objective basis. The entropy evaluation method is completely objective for weight setting on the basis of data, but it is not necessarily in line with the conventional facts. Therefore, it is of great significance to set weight combining subjective and objective data or improve the method of setting weight.

\section{REFERENCES}

Lian Y. M., Wu J. Z., 2011. China National Conditions Report: 2010-2011[M]. Beijing: China Modern Economics Publishing House.

Zhang J. X., Liu J. P., 2011. Reflections on Monitoring of Geographic Conditions [N]. China Surveying and Mapping News.

Zhang J. X., Li W. S., Zhai L., 2015, Understanding geographic conditions monitoring a perspective from China[J]. International Journal of DigitalEarth, 8(1), pp. 38-57.

Zhao F., 2011. Discussion of Geographic Situation Surveying Work in Shanghai[J]. Shanghai Land \& Resources, 32(3), pp. 74-76.

Xu D. M., 2011. Monitoring Geographic Conditions for Serving Scientific Development $[\mathrm{N}]$. China Surveying and Mapping News.

Li X. W., X D. N., Hu Y. M., 2002. The Analysis and Evaluation of Land Use Scenarios in the Liaohe River Delta Wetlands [J]. Acta Ecologica Sinica, 22(2), pp. 224-232.

Li D. R., 2011. Discussion on Key Technologies of Monitoring National Geographic Conditions. Prepared by: China Surveying and Mapping Propaganda Center. Research and Exploration on Monitoring Geographic Conditions. Beijing: Surveying and Mapping Publishing House, pp. 19-25.

Liu Y. L., He J. H., 2014. Design of the Hierarchical Index System for National Geographic Conditions Statistics [J]. Geospatial Information, 12(3), pp. 1-4.

2013. General Survey Content and Index of National Geographic Conditions[S]. The First National Geographic Conditions Survey Leading Office of the State Council (NGCSLO).

Chen S. Y., 2015. The evaluation indicator of ecological development transition in China's regional economy [J]. Ecological Indicators, (51), pp. 42-52. 
Cheng J. Y., 2014. Reflections on Surveying of Geographic Conditions [J]. Geospatial Information, 12(2), pp. 1-3.

Xie H. L., Yao G. R., Liu G. Y., 2015. patial evaluation of the ecological importance based on GIS for environmental management-A case study in Xingguo county of China [J]. Ecological Indicators, (51), pp. 3-12.

WU C., 2012. Research on Content Classification and Construction of Index System of Geographic National Condition Monitoring [D]. Shandong Agricultural University.

2013. Regulations on Basic Statistical Techniques of Geographic Conditions Survey[R]. Chinese Academy of Surveying and Mapping (CASM).

Li X. J., 2006. Economic Geography (second edition) [M]. Beijing: Higher Education Press.

Zhu X. Y., Chen Y. Q., 2011. SPSS Multivariate Statistical Analysis Method and Application [M]. Beijing: Tsinghua University Press.

Shnitnikov A. S., 2001. Measurement Techniques, 44(2), pp. 135.

Sun L. J., 2012. Exploration and Practice of Geographic Conditions Monitoring Framework [J]. Surveying and Mapping Bulletin, (8), pp. 62-64.

Lu N. Y., Yang Y. H., Wang F. L., 2002. Research and Implementation of Process Monitoring Based on Iterative Principal Component Analysis (PCA) [J]. Control and Decision, 17(2), pp. 215-218.

Cai Y., 2005. Application of Principal Component Analysis in Comprehensive Evaluation [J]. China Statistics, (2), pp. 24-26. 